\title{
Pulley Device
}

National Cancer Institute

\section{Source}

National Cancer Institute. Pulley Device. NCI Thesaurus. Code C50126.

A wheel with a groove in it designed to change the direction of force of a rope or belt that runs over it. 